Supplementary Material for

Increase in Fluorophore:Dendrimer Ratio Decreases Cellular Uptake of Neutral Dendrimers in RAW cells not HEK293A cells

Sriram Vaidyanathan ${ }^{1}$, Milan Kaushik ${ }^{2}$, Casey Dougherty ${ }^{2}$, Rahul Rattan ${ }^{3}$, Sascha Goonawardena $^{3^{*}}$, Mark M Banaszak Holl ${ }^{1,2^{*}}$

Janet Monano ${ }^{4}$, Stassi DiMaggio ${ }^{4 *}$

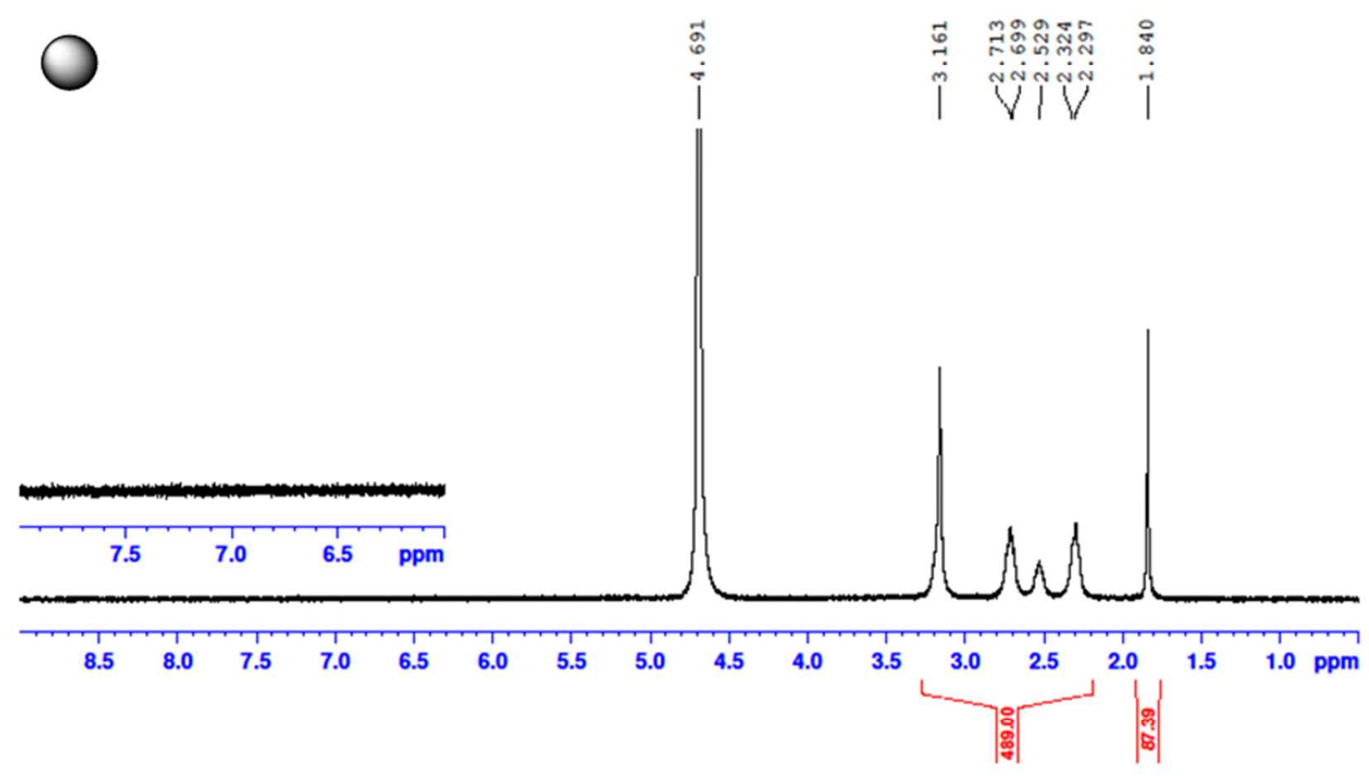




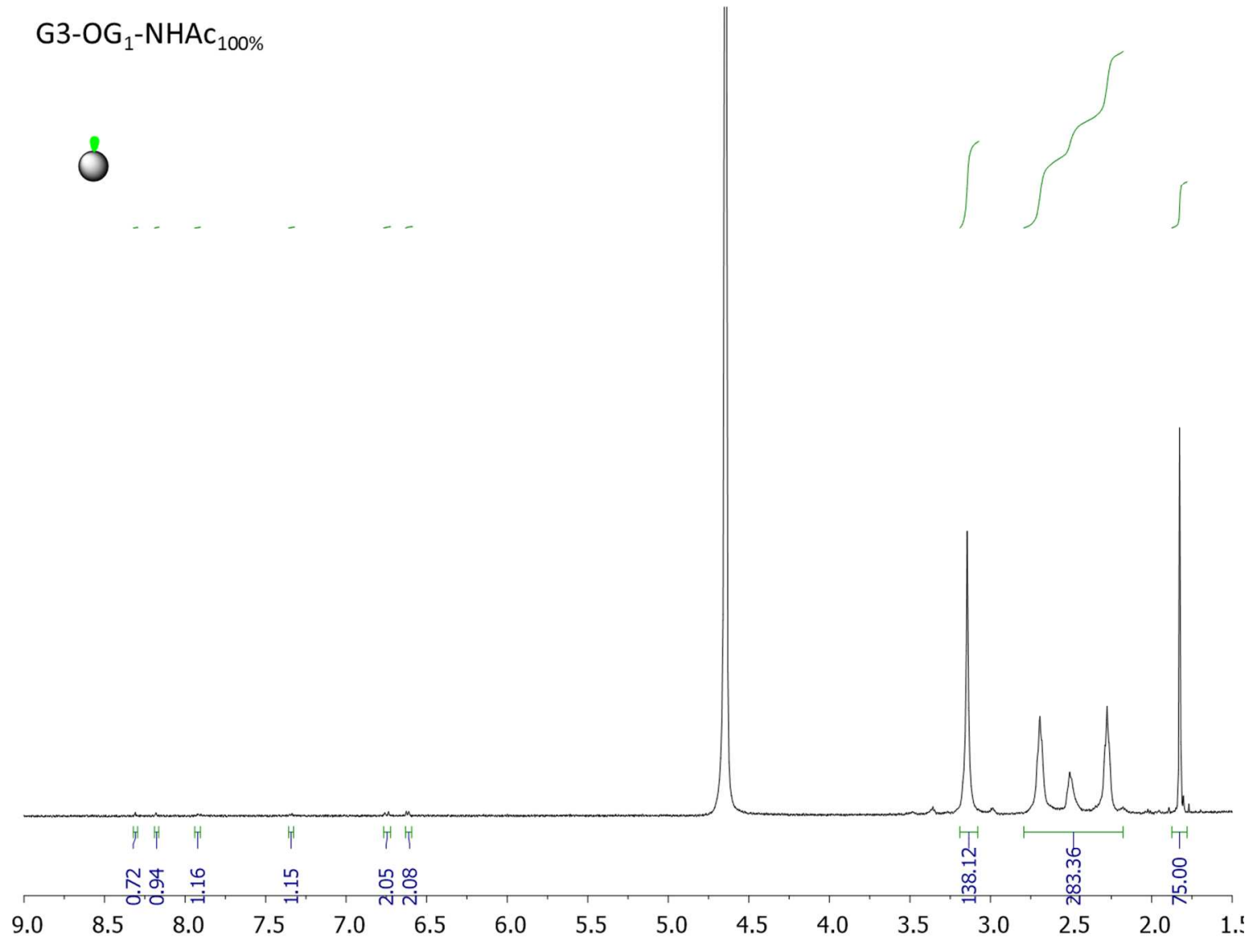




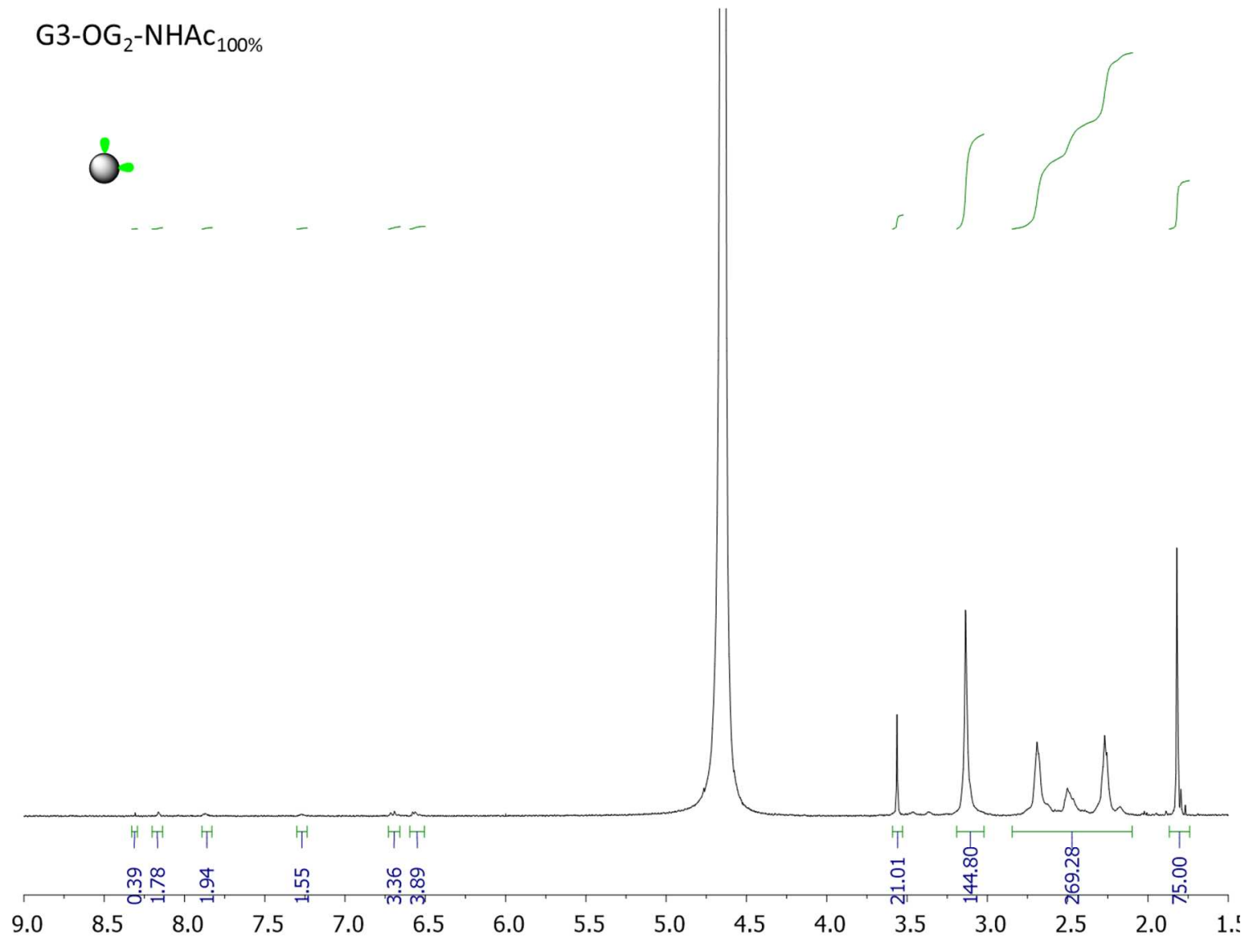




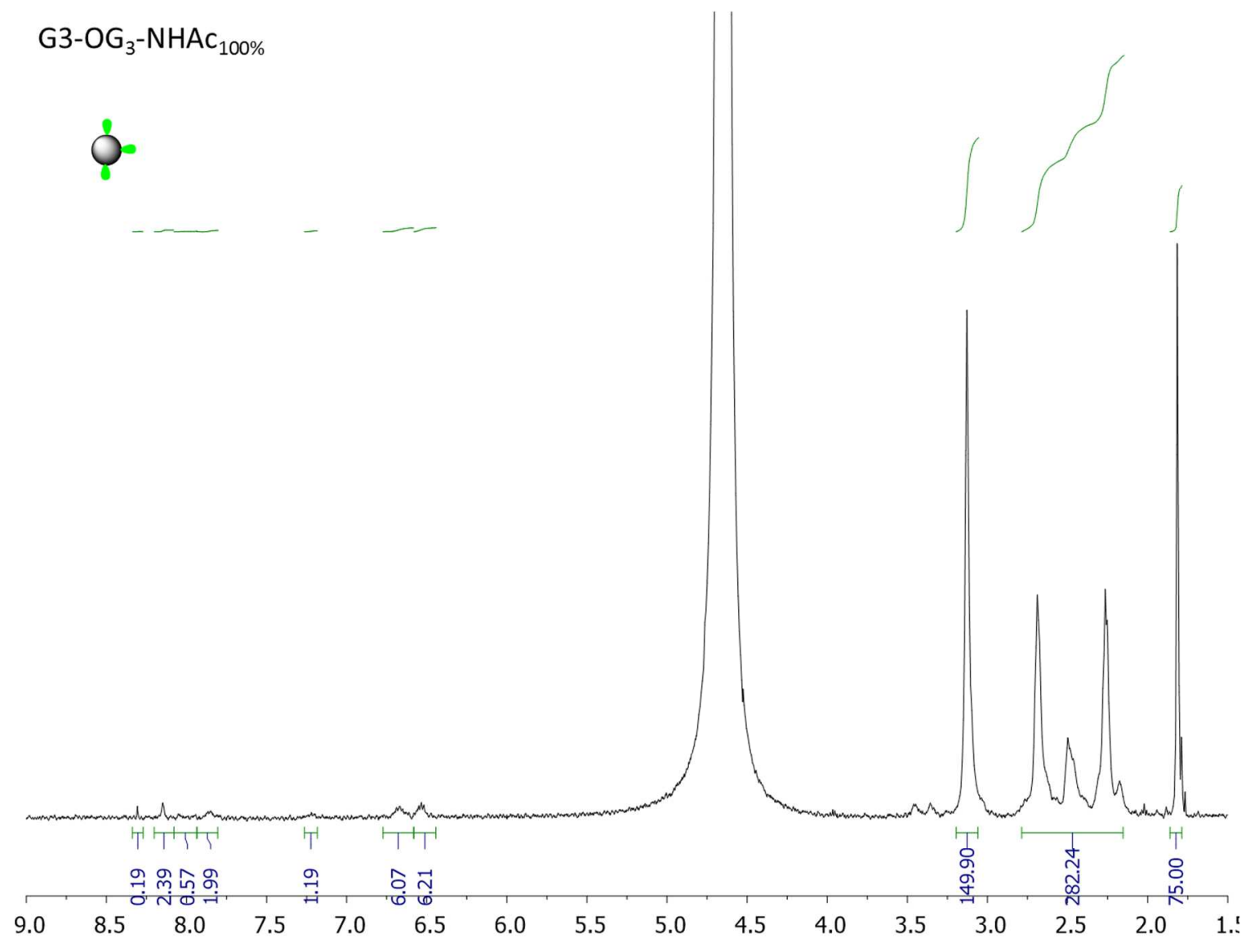




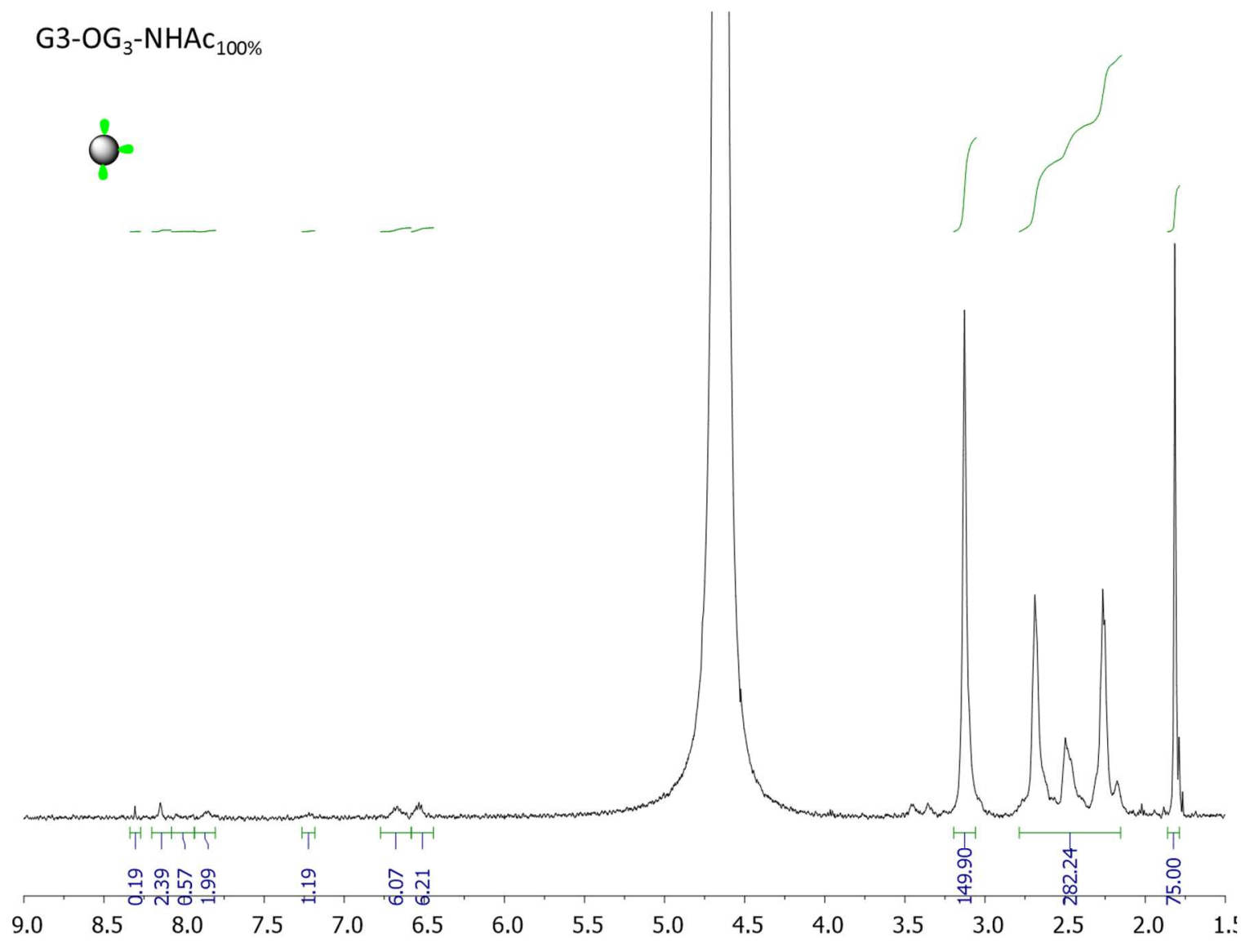




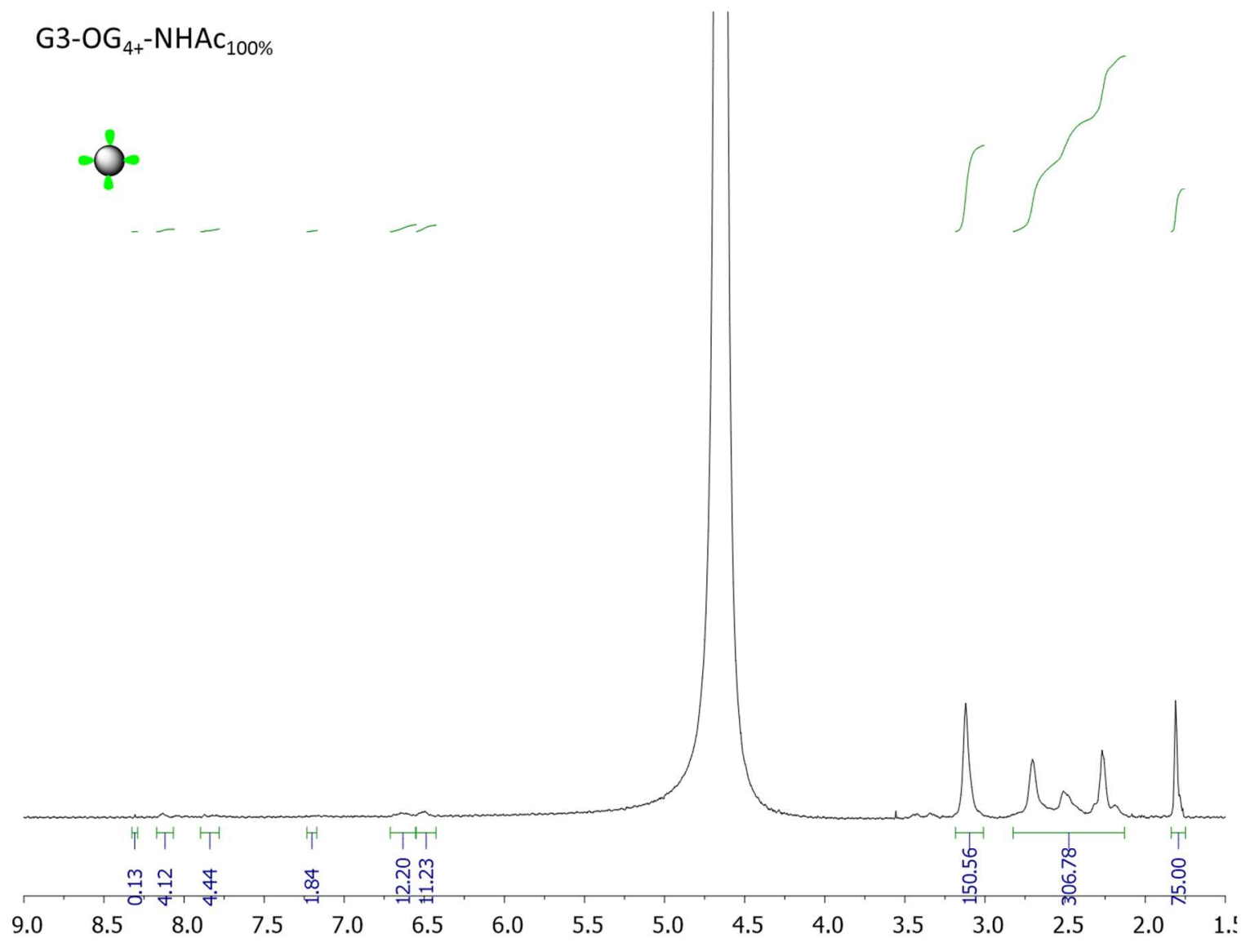




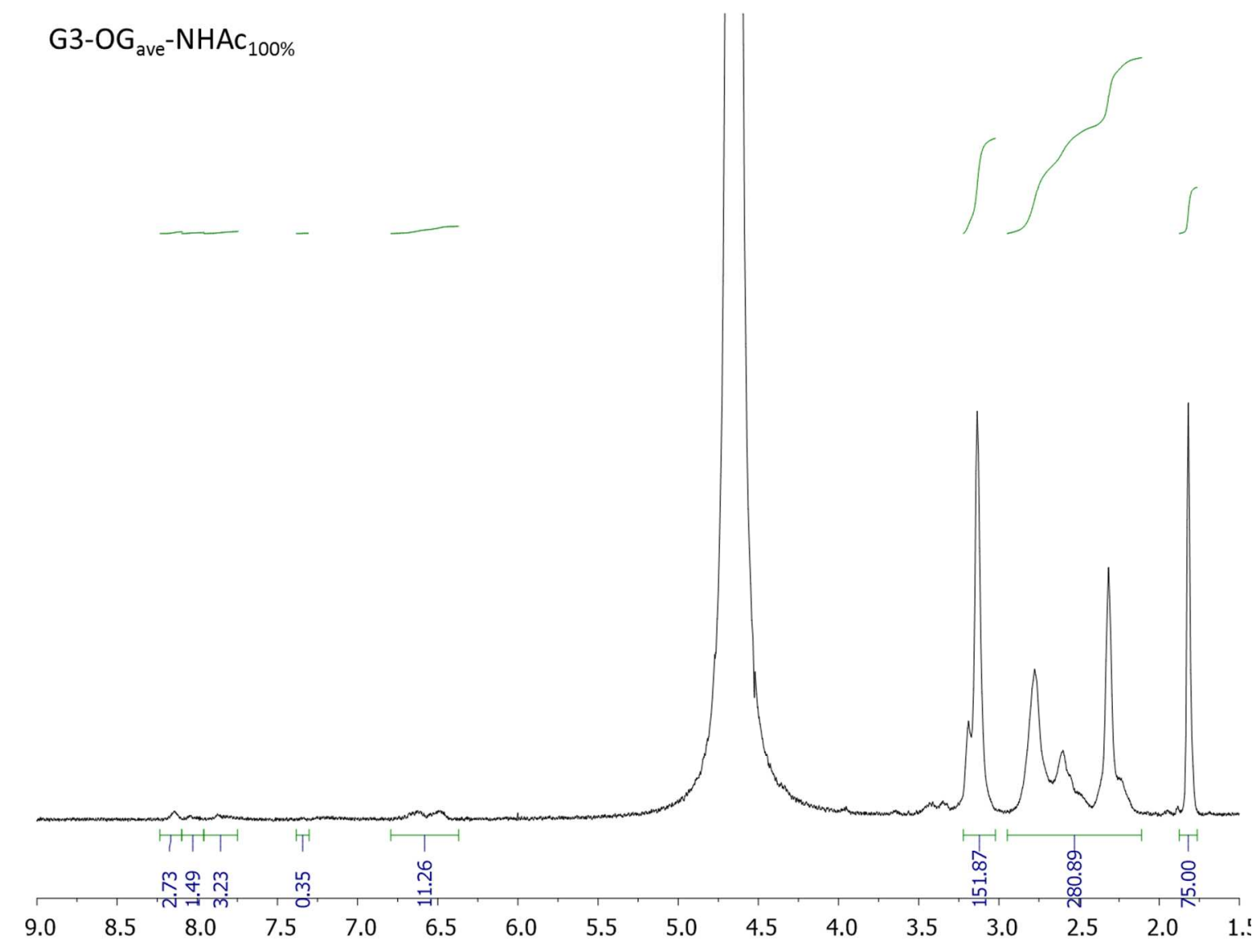

Figure S1: $1 \mathrm{H}$ NMR Spectra of $\mathrm{NMR}$ of $\mathrm{G3}^{-}-\mathrm{OG}_{\mathrm{n}}(\mathrm{n}=0-4+$, average $)$ in $\mathrm{D}_{2} \mathrm{O}$ at $500 \mathrm{MHz}$.

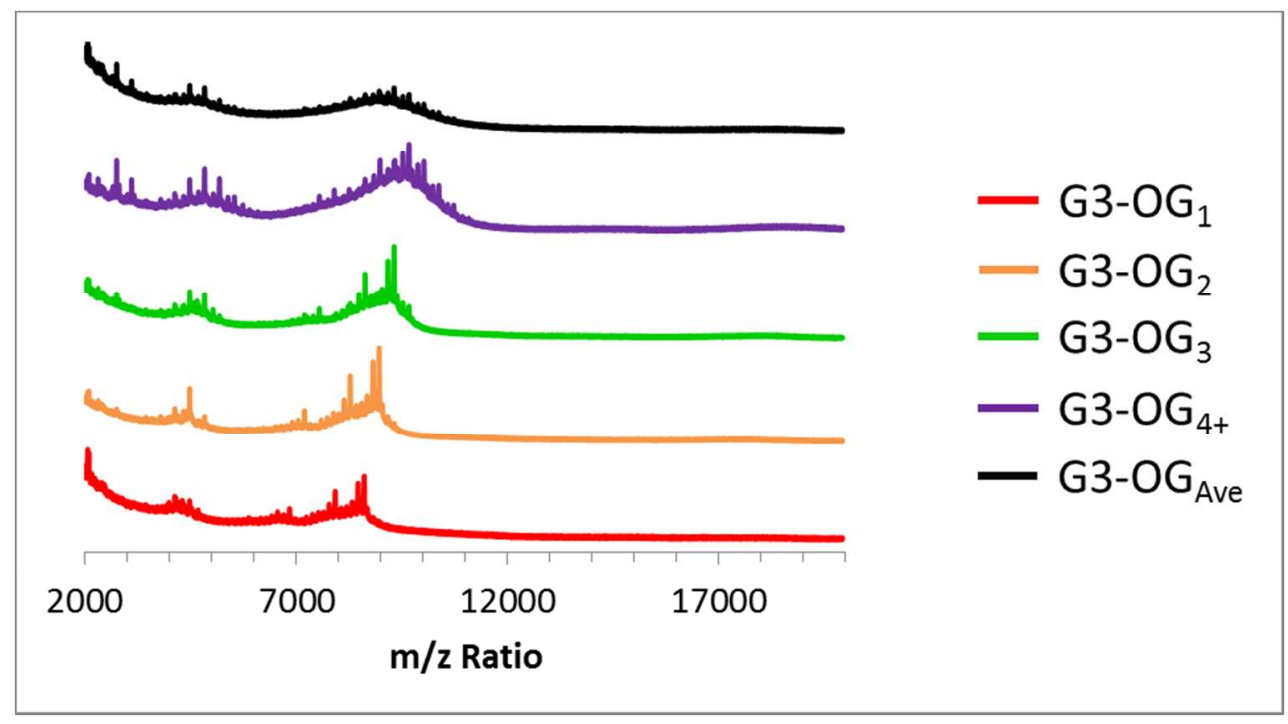

Figure S2: MALDI-TOF-MS spectra of $\mathrm{G} 3-\mathrm{OG}_{\mathrm{n}}$ materials. Numbers for $\mathrm{m} / \mathrm{z}$ ratios for each sample are reported in Table 1. 


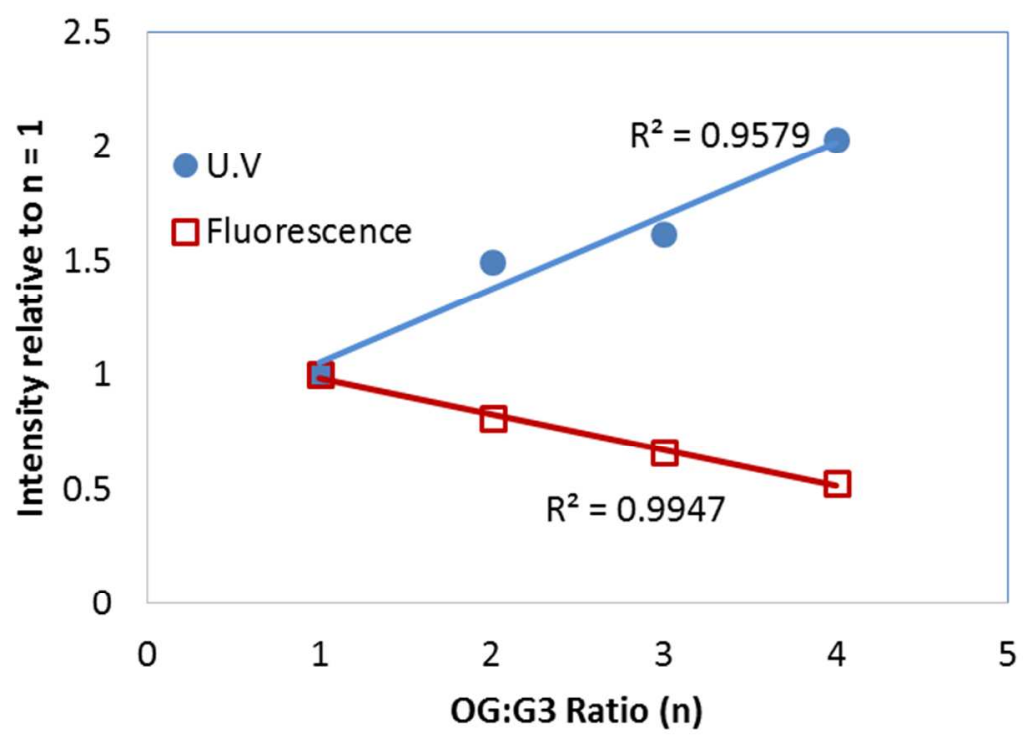

Figure S3: The UV/vis absorption increases linearly with increases OG:G3 ratio and fluorescence emission decreases linearly.

Table S1: Statistical results from One-way ANOVA followed by Games Howell tests for RAW cells

\begin{tabular}{llllll}
\hline \multicolumn{7}{c}{ Uncorrected Raw } \\
\hline G3-OG $_{\mathbf{1}}$ & N/A & S & S & S & S \\
\hline G3-OG $_{2}$ & S & N/A & S & S & S \\
\hline G3-OG $_{3}$ & S & S & N/A & S & N.S \\
G3-OG4 $_{+}$ & S & S & S & N/A & S \\
\hline G3-OG $_{\text {Ave }}$ & S & S & N.S & S & N/A \\
\hline
\end{tabular}


Table S2: Statistical results from One-way ANOVA followed by Games Howell tests for HEK293A cells

\section{Uncorrected HEK}

\begin{tabular}{llllll} 
& G3-OG1 & G3-OG2 & G3-OG3 & G3-OG4+ & G3-OGAve \\
\hline G3-OG1 & N/A & N.S & S & S & S \\
\hline G3-OG2 & N.S & N/A & S & S & S \\
\hline G3-OG3 & S & S & N/A & N.S & S \\
\hline G3-OG4+ & S & S & N.S & N/A & S \\
\hline G3-OGAve & S & S & S & S & N/A \\
\hline
\end{tabular}

Table S3: Statistical results from One-way ANOVA followed by Games Howell tests for RAW cells

\begin{tabular}{llllll}
\hline \multicolumn{5}{c}{ Corrected Raw } \\
\hline G3-OG1 & G3-OG1 & G3-OG2 & G3-OG3 & G3-OG4+ & G3-OGAve \\
\hline G3-OG2 & N.S & N.S & S & S & S \\
\hline G3-OG3 & S & S & S & S & S \\
\hline G3-OG4+ & S & S & N.S & N.S & N.S \\
\hline G3-OGAve & S & S & N.S & N.S & N.S \\
\hline
\end{tabular}

Table S4: Statistical results from One-way ANOVA followed by Games Howell tests for HEK293A cells

\begin{tabular}{llllll}
\hline \multicolumn{5}{c}{ Corrected HEK } \\
\hline G3-OG1 & G3-OG1 & G3-OG2 & G3-OG3 & G3-OG4+ & G3-OGAve \\
\hline G3-OG2 & S & S & N.S & N.S & N.S \\
\hline G3-OG3 & N.S & S & N/A & N.S & N.S \\
\hline G3-OG4+ & N.S & N.S & N.S & N/A & N.S \\
\hline G3-OGAve & N.S & N.S & N.S & N.S & N/A \\
\hline
\end{tabular}

S- Statistically significant difference, N.S -Not statistically significant difference, N/A- not applicable 